\title{
Coronary Heart Disease in Men and Women: Does 1 Size Fit All? No!
}

\author{
Nanette K. Wenger, MD, MACC, MACP, FAHA \\ Department of Medicine (Cardiology), Emory University School of Medicine, and Emory Heart and \\ Vascular Center, Atlanta, Georgia
}

I am delighted to have the opportunity to debate my valued friend and colleague, Dr. Ezra Amsterdam, addressing the query, "Coronary heart disease in men and women: does 1 size fit all?" I reply with a resounding "No!"

\section{Demography}

In characterizing the feminine face of coronary heart disease (CHD), it is vital to note that, since 1984, the annual number of cardiovascular (CV) deaths for women has exceeded that for men. Among women, CHD is not only lethal, but is a substantial contributor to morbidity, disability, hospitalizations, and office visits for women. ${ }^{1}$

Cardiovascular disease (CVD) is the leading cause of death in women, as it is in men, although the initial clinical manifestations of coronary disease appear on average 10 years later in women. Coronary prevalence rises steeply with increasing age, such that 1 of 3 to 4 US women will eventually die of a coronary event.

Impressively, $\mathrm{CV}$ mortality has declined annually among women since 2000, even more steeply than among men, due to a combination of improved management of established CHD, including secondary preventive therapy, and improved reduction of major coronary risk factors. ${ }^{2}$

\section{Should Women Have Different Risk Assessment for Primary Prevention?}

Two of 3 women in the United States have $\geq 1$ major coronary risk factor, and this percentage increases with older age. Noteworthy are the adverse trends in CVD risk factors among women. ${ }^{3,4}$ Diabetes (DM) is a far more devastating risk factor for women than men for myocardial infarction (MI) and stroke. There is a 3- to 7-fold increased CV risk in diabetic vs nondiabetic women, in contrast to an only 2- to 4-fold increase in risk for diabetic vs nondiabetic men. Cigarette smoking triples the risk of MI for women, yet smoking cessation has been less prominent among women than men. Low levels of high-density lipoprotein cholesterol and high levels of triglycerides better predict $\mathrm{CHD}$ in women than in men. A higher percentage of elderly women than men have hypertension - almost $80 \%$ of women age $>75$ years, particularly isolated systolic hypertension. Physical inactivity is the most prevalent risk factor for

The author has no funding, financial relationships, or conflicts of interest to disclose. women, and almost 2 of 3 US women are currently overweight or obese.

Recent years have seen an increasing coronary death rate in younger adults, with this increase more prominent for women than for men, likely related substantially to the obesity epidemic. ${ }^{5}$ Specifically, for women in the $35-54$-year age group, between 1980 and 1989 CHD mortality decreased by $5.4 \%$, and between 1989 and 2000 by $1.2 \%$; but in $2000-2002$, the mortality trend was an increase of $1.5 \%$. By contrast, for men age 35-54 years, the decline in coronary mortality between 1980 and 1989 was 6.2\%; between 1989 and 2000, 2.3\%; and in the years $2000-2002,0.5 \%$. These changes have occurred concomitantly with a spectrum of unfavorable coronary risk factor changes, predominantly the increase in obesity noted previously, but DM, hypertension, and the metabolic syndrome as well. Ford called this "the leading edge of a brewing storm," portending further unfavorable mortality trends as this population ages. ${ }^{5}$

The National Cholesterol Education Program-Adult Treatment Panel III (NCEP-ATP III) ${ }^{6}$ comparably defines gender differences in its recommendations. The age at risk for women is $\geq 55$ years, and for men $\geq 45$ years. Premature coronary disease in a first-degree relative is defined as $<$ age 65 years for women, and <age 55 years for men. A low high-density lipoprotein cholesterol is characterized as $<50 \mathrm{mg} / \mathrm{dL}$ for women, but $<40 \mathrm{mg} / \mathrm{dL}$ for men, and an increased waist circumference as $>35$ inches for women, and $>40$ inches for men.

Complications of pregnancy and resultant coronary and $\mathrm{CV}$ risk pose a problem unique to women. Increasingly, pregnancy is recognized as a CV and metabolic stress. ${ }^{7-9}$ Preeclampsia and gestational hypertension increase coronary risk, being associated with a $2.6 \times$ increase in fatal myocardial ischemic events, a 3-6x increased risk of subsequent hypertension, and a 3 -fold increase in the risk of subsequent DM. Gestational diabetes is associated with 7-fold increase in the risk of subsequently developing type $2 \mathrm{DM}$.

Menopausal hormone therapy, as well, poses a risk unique to women. In the Heart and Estrogen/Progestin Replacement Study (HERS), there was no decrease in risk of CVD with estrogen/progestin among women with known $\mathrm{CHD}$. The outcome in healthy women was reported from the Women's Health Initiative (WHI), wherein menopausal hormone therapy increased the risk of MI, stroke, and venous thromboembolism. ${ }^{10}$ The menopausal hormone therapy results of WHI can be summarized as follows: for the estrogen + progestin arm of the study, reported in July $2002,{ }^{10}$ combination hormone therapy increased the risk of 
heart attack, breast cancer, blood clots, and stroke, as well as dementia and ovarian cancer. There was a lessened risk of hip fracture, colorectal cancer, and endometrial cancer, and no effect on the quality of life. The estrogen-only arm of WHI, in women who had had hysterectomy, was reported in March 2004 and showed an increased risk of stroke and of probable dementia or memory loss, a decrease in hip fracture, and no effect on breast cancer or heart disease.

Of interest for women, pregnancy-related behaviors may decrease CV risk. Data from the WHI involving 139681 menopausal women ${ }^{11}$ showed that breast-feeding was protective against CVD. Total breast-feeding of $>12$ months decreased by $72 \%$ the risk of CVD, and was associated with decreased prevalence of hypertension, DM, and hyperlipidemia. The longer the lactation, the lower the risk factors.

\section{Aspirin for Primary Prevention}

Aspirin is routinely recommended for the primary prevention of CHD in men, but not in women. In the Physicians' Health Study, the men had benefit from $325 \mathrm{mg}$ of aspirin every other day for MI, but not for stroke. By contrast, in the Women's Health Study, involving 39876 healthy lowrisk women age $>45$ years, aspirin in a dosage of $100 \mathrm{mg}$ every other day was shown to prevent stroke, but not MI or CV death before age 65 years $^{12}$; the potential for gastrointestinal bleeding was cited as a risk. After age 65 years, there was a slight prevention of stroke, MI, and CV death for women, but this was virtually negated by the increased risk of gastrointestinal bleeding, prompting the authors to recommend individualization of aspirin use. ${ }^{13}$

\section{Noncoronary Cardiovascular Risk for Women}

Stroke poses a major CV risk for women, with stroke events greater than coronary events in women prior to 75 years of age, but the opposite evident for men. Stroke death in women exceeds that in men. ${ }^{14}$

Atrial fibrillation is associated with a 4- to 5-fold increase in the risk of embolic stroke, and undertreatment with anticoagulants doubles the risk of recurrent stroke. Undertreatment with anticoagulants is a common problem for women.

\section{Special Contributors to Cardiovascular Risk in Women}

Depression and other psychosocial risk factors, more common in women than in men, contribute to $\mathrm{CV}$ risk in women. The same is true for autoimmune diseases, particularly lupus erythematosus and rheumatoid arthritis. ${ }^{15}$ Women with these problems should be considered as at risk and screened for $\mathrm{CV}$ risk factors. ${ }^{16}$

\section{Awareness of Coronary Risk in Women}

In the $1990 \mathrm{~s}, 4$ of 5 US women and 1 of 3 of their primary care physicians were unaware that $\mathrm{CHD}$ was the major cause of death for women. Educational campaigns by the American Heart Association and the National Heart, Lung, and Blood Institute, among others, have increased this awareness of women from $30 \%$ in 1997 to $54 \%$ in
2009. Nonetheless, awareness is lower in the highest-risk populations, black women, as compared with white women. Equally of concern ${ }^{17}$ is that in a recent national survey by the American Heart Association, only $53 \%$ of women queried would call 911 for symptoms of MI.

\section{Clinical Challenges in Women With Established Coronary Heart Disease}

There is an increased frequency, severity, and mortality of chronic stable angina in women compared with men. As well, acute coronary syndromes (ACS) entail an excess of complications, mortality, heart failure, stroke, and transfusion requirement among women. Women receive fewer evidenced-based beneficial therapies and referrals to cardiac rehabilitation following hospitalization for ACS.

The excess mortality of younger women, specifically those age $<50$ years, as compared with men, following both MI and coronary artery bypass graft surgery, remains unexplained. ${ }^{18-22}$ The increase in early mortality of women with ST-elevation MI relates substantially to the underuse of evidence-based treatments and delayed reperfusion. ${ }^{23}$

\section{What Is the Role of Underlying Anatomic and Pathophysiologic Gender Differences?}

Women have less obstructive coronary artery disease, yet more diffuse atherosclerosis at angiography than do men. ${ }^{24}$

The Women's Ischemia Syndrome Evaluation (WISE) highlighted the importance of microvascular disease for women. ${ }^{25}$ To be enrolled in the WISE trial, women were required to have chest pain and evidence of ischemia at noninvasive testing, but many lacked obstructive coronary artery disease at coronary angiography. Despite the lack of obstructive coronary disease, there was a $9.4 \%$ occurrence of $\mathrm{MI}$ and/or coronary death at 4 years, with persistent pain without coronary obstructive disease predicting $\mathrm{CV}$ events. $^{25,26}$ Note that comparable data are unavailable for men.

As well, autopsy studies in younger women who died suddenly showed more plaque erosion than plaque rupture, with the potential for distal microvascular embolization. ${ }^{27,28}$ The plaque characteristics of older women who died suddenly were much more comparable to those for men. As well, laboratory studies of women show an increase in thrombotic risk and an increase in levels of inflammation.

The Framingham Risk Score traditionally underestimates the $\mathrm{CV}$ risk for women, likely owing to its focus on intermediate-term (10-year) risk and its reliance on endpoints of MI and coronary death. Consideration of family history is not included. As a result, even women with evidence of subclinical atherosclerosis are often classified as at low risk by the Framingham Risk Score.

In the 2011 Update, women are classified either as "high risk", "at risk", or at ideal cardiovascular health. Identification of the high-risk woman, in addition to the presence of clinically manifest $\mathrm{CV}$, cerebrovascular, or peripheral arterial disease, and abdominal aortic aneurysm, end-stage or chronic kidney disease, and DM, includes a 10 -year predicted $\mathrm{CV}$ risk of $\geq 10 \%$ (in contrast to the prior 10 -year predicted risk for $\mathrm{CHD}$ of $>20 \%)$. The presence of 


\begin{tabular}{|c|c|}
\hline Risk Status & Criteria \\
\hline \multirow{7}{*}{$\begin{array}{l}\text { High risk ( } \geq 1 \\
\text { high-risk states) }\end{array}$} & Clinically manifest $\mathrm{CHD}$ \\
\hline & Clinically manifest cerebrovascular disease \\
\hline & Clinicaily manifest peripheral arterial disease \\
\hline & Abdominal aortic aneurysm \\
\hline & End-stage or chronic kidney disease \\
\hline & Diabetes mellitus \\
\hline & 10 -y Predicted CVD risk $\geq 10 \%$ \\
\hline \multirow{12}{*}{$\begin{array}{l}\text { At risk ( } \geq 1 \text { major } \\
\text { risk factor[s]) }\end{array}$} & Cigarette smoking \\
\hline & $\begin{array}{l}\mathrm{SBP} \geq 120 \mathrm{~mm} \mathrm{Hg}, \mathrm{DBP} \geq 80 \mathrm{~mm} \mathrm{Hg} \text {, or treated } \\
\text { hypertension }\end{array}$ \\
\hline & $\begin{array}{l}\text { Total choiesterol } \geq 200 \mathrm{mg} / \mathrm{dL} \text {, HDL-C }<50 \\
\mathrm{mg} / \mathrm{dL} \text {, or treated for dyslipidemia }\end{array}$ \\
\hline & Obesity, particularly central adiposity \\
\hline & Poor diet \\
\hline & Physical inactivity \\
\hline & $\begin{array}{l}\text { Family history of premature CVD occurring in } \\
\text { first-degree relatives in men }<55 \text { y of age or } \\
\text { in women }<65 \text { y of age }\end{array}$ \\
\hline & Metabolic syndrome \\
\hline & $\begin{array}{l}\text { Evidence of advanced subclinical atherosclerosis } \\
\text { (eg, coronary calcification, carotid plaque, or } \\
\text { thickened IMT) }\end{array}$ \\
\hline & $\begin{array}{l}\text { Poor exercise capacity on treadmill test and/or } \\
\text { abnormal heart rate recovery after stopping } \\
\text { exercise }\end{array}$ \\
\hline & $\begin{array}{l}\text { Systemic autoimmune collagen-vascular disease } \\
\text { (eg, lupus or meumatoid arthritis) }\end{array}$ \\
\hline & $\begin{array}{l}\text { History of preeclampsia, gestational diabetes, or } \\
\text { pregnancy-induced hypertension }\end{array}$ \\
\hline \multirow{7}{*}{$\begin{array}{l}\text { Ideal cardiovascular } \\
\text { health (all of these) }\end{array}$} & Total cholesterol $<200 \mathrm{mg} / \mathrm{dL}$. (untreated) \\
\hline & $\mathrm{BP}<120 /<80 \mathrm{~mm} \mathrm{Hg}$ (untreated) \\
\hline & Fasting blood glucose $<100 \mathrm{mg} / \mathrm{dL}$ (untreated) \\
\hline & Body mass index $<25 \mathrm{~kg} / \mathrm{m}^{2}$ \\
\hline & Abstinence from smoking \\
\hline & $\begin{array}{l}\text { Physical activity at goal for adults }>20 \text { y of age: } \\
\geq 150 \mathrm{~min} / \text { wk moderate intensity, } \geq 75 \\
\mathrm{~min} / \mathrm{wk} \text { vigorous intensity, or combination }\end{array}$ \\
\hline & Healthy (DASH-like) diet \\
\hline
\end{tabular}

CVD indicates cardiovascular disease; CHD, coronary heart disease; SBP, systolic blood pressure; DBP, diastolic blood pressure; HDL-C; high-density lipoprotein cholesterol; IMT, intima-media thickness; BP, blood pressure; and DASH, Dietary Approaches to Stop Hypertension.

\section{Source: Mosca, Circulation $2011 ; 123: 1243$}

Figure 1. Flow diagram for CVD preventive care in women. Abbreviations: ACS, acute coronary syndrome; CHD, coronary heart disease; CVD, cardiovascular disease; DASH, Dietary Approaches to Stop Hypertension; HDL-C, high-density lipoprotein cholesterol; LDL-C, low-density lipoprotein cholesterol. Reprinted by permission from Mosca L et al. ${ }^{16}$

$\geq 1$ major risk factor defines the population of women at risk, and includes the issues of autoimmune disease and pregnancy-related complications previously addressed.

The new concept of "ideal cardiovascular health" encompasses absence of clinical CVD and ideal levels of total cholesterol, blood pressure, and fasting glucose, coupled with adherence to heart-healthy behaviors, including a lean body mass index, smoking abstinence, participation in physical activity at recommended goals, and a heart-healthy diet (Figure 1). 


\section{Summary}

Clearly, women are at increased coronary and CV risk, most predominantly at older age, although the young woman (age $<50 \mathrm{y}$ ) is more likely to incur fatality following MI and coronary artery bypass graft surgery than the young man. Substantial disparity exists in the risk imparted by specific traditional coronary risk factors. Additionally, women have the unique risks posed by pregnancy and by menopausal hormone therapy. Clearly, one size does not fit all.

\section{References}

1. Roger VL, Go S, Lloyd-Jones DM, et al; on behalf of the American Heart Association Statistics Committee and Stroke Statistics Subcommittee. Heart disease and stroke statistics - 2011 update: a report from the American Heart Association. Circulation. 2011;123:e18-e209.

2. Ford ES, Ajani UA, Croft JB, et al. Explaining the decrease in U.S. deaths from coronary disease, 1980-2000. N Engl J Med. 2007;356:2388-2398.

3. Hokanson JE, Austin MA. Plasma triglyceride level is a risk factor for cardiovascular disease independent of high-density lipoprotein cholesterol level: a meta-analysis of population-based prospective studies. J Cardiovasc Risk. 1996;3:213-219.

4. Wenger NK. Should women have a different risk assessment from men for primary prevention of coronary heart disease? J Womens Health. 1999;8:465-467.

5. Ford ES, Capewell S. Coronary heart disease mortality among young adults in the U.S. from 1980 through 2002: concealed leveling of mortality rates. J Am Coll Cardiol. 2007;50:2128-2132.

6. Third Report of the National Cholesterol Education Program (NCEP) Expert Panel on Detection, Evaluation, and Treatment of High Blood Cholesterol in Adults (Adult Treatment Panel III) final report. Circulation. 2002;106:3143-3421.

7. Bellamy L, Casas JP, Hingorani $\mathrm{AD}$, et al. Pre-eclampsia and risk of cardiovascular disease and cancer in later life: systematic review and meta-analysis. BMJ. 2007;335:974-985.

8. Roberts JM, Hubel CA. Pregnancy: a screening test for later life cardiovascular disease. Womens Health Issues. 2010;20:304-307.

9. Lykke JA, Langhoff-Roos J, Sibai BM, et al. Hypertensive pregnancy disorders and subsequent cardiovascular morbidity and type 2 diabetes mellitus in the mother. Hypertension. 2009;53:944-951.

10. Writing Group for the Women's Health Initiative Investigators. Risks and benefits of estrogen plus progestin in healthy postmenopausal women: principal results from the Women's Health Initiative randomized controlled trial. JAMA. 2002;288:321-333.

11. Schwarz EB, Ray RM, Stuebe AM, et al. Duration of lactation and risk factors for maternal cardiovascular disease. Obstet Gynecol. 2009;113:974-982.

12. Ridker PM, Cook NR, Lee IM, et al. A randomized trial of lowdose aspirin in the primary prevention of cardiovascular disease in women. N Engl J Med. 2005;352:1293-1304.

13. Berger JS, Roncaglioni MC, Avanzini, et al. Aspirin for the primary prevention of cardiovascular events in women and men: a sexspecific meta-analysis of randomized controlled trials. JAMA. 2006;295:306-313.

14. Wann LS, Curtis AB, January CT, et al. 2011 ACCF/AHA/HRS focused update on the management of patients with atrial fibrillation (updating the 2006 guideline): a report of the American College of Cardiology Foundation/American Heart Association Task Force on Practice Guidelines. Circulation. 2011;123: 104-123.

15. Salmon JE, Roman MJ. Subclinical atherosclerosis in rheumatoid arthritis and systemic lupus erythematosus. Am J Med. 2008;121:S3-S8.

16. Mosca L, Benjamin EJ, Berra K, et al. Effectiveness-based guidelines for the prevention of cardiovascular disease in women-2011 update: a guide from the American Heart Association. Circulation. 2011;123:1243-1262.

17. Mosca L, Mochari-Greenberger H, Dolor RJ, et al. Twelve-year follow-up of American women's awareness of cardiovascular disease risk and barriers to heart health. Circ Cardiovasc Qual Outcomes. 2010;3:120-127.

18. Vaccarino V, Parsons L, Every NR, et al; for the National Registry of Myocardial Infarction 2 Participants. Sex-based differences in early mortality after myocardial infarction. $N$ Engl $\mathrm{JMed}$. 1999;341:217-225.

19. Vaccarino V, Abramson JL, Veledar E, et al. Sex differences in hospital mortality after coronary artery bypass surgery: evidence for a higher mortality in younger women. Circulation. 2002;105:1176-1181.

20. Daly C, Clemens F, Sendon JL, et al; on behalf of the Euro Heart Survey Investigators. Gender differences in the management and clinical outcome of stable angina. Circulation. 2006;113:490-498.

21. Blomkalns AL, Chen AY, Hochman JS, et al; for the CRUSADE Investigators. Gender disparities in the diagnosis and treatment of non-ST-segment elevation ACS: large-scale observations from the CRUSADE (Can Rapid Risk Stratification of Unstable Angina Patients Suppress Adverse Outcomes with Early Implementation of the American College of Cardiology/American Heart Association Guidelines) National Quality Improvement Initiative. J Am Coll Cardiol. 2005; 45:832-837.

22. Anderson JL, Adams CD, Antman EM, et al. ACC/AHA 2007 guidelines for the management of patients with unstable angina/non-ST-elevation myocardial infarction: a report of the American College of Cardiology/American Heart Association Task Force on Practice Guidelines (Writing Committee to Revise the 2002 Guidelines for the Management of Patients with Unstable Angina/Non-ST-Elevation Myocardial Infarction). J Am Coll Cardiol. 2007;50:e1-e157.

23. Jneid H, Fonarow GC, Cannon CP, et al; for the Get With the Guidelines Steering Committee and Investigators. Sex differences in medical care and early death after acute myocardial infarction. Circulation. 2008;118:2803-2810.

24. Wenger NK. Angina in women. Curr Cardiol Rep. 2010;12: 307-314

25. Challenging existing paradigms in ischemic heart disease: the NHLBI-sponsored Women's Ischemia Syndrome Evaluation (WISE). J Am Coll Cardiol. 2006;47(suppl S):S1-S72.

26. Pepine CJ, Anderson RD, Sharaf BL, et al. Coronary microvascular reactivity to adenosine predicts adverse outcome in women evaluated for suspected ischemia: results from the National Heart, Lung, and Blood Institute WISE (Women's Ischemia Syndrome Evaluation) Study. J Am Coll Cardiol. 2010;55:2825-2832.

27. Burke AP, Farb A, Malcom GT, et al. Effect of risk factors on the mechanism of acute thrombosis and sudden coronary death in women. Circulation. 1998;97:2110-2116.

28. Kramer MC, Rittersma SZ, de Winter RJ, et al. Relationship of thrombus healing to underlying plaque morphology in sudden coronary death. I Am Coll Cardiol. 2010;55:122-132. 


\section{Rebuttal: It's All About Finding Solutions}

Ezra, as my rebuttal highlighting “All About Eve,” I chose to stress that it is all about finding solutions. Indeed, solutions are best typified by a famous New Yorker cartoon showing Adam and Eve in the Garden of Eden. With the serpent looking at both of them, Adam eating the apple, his comment to Eve is: "Hey! I just figured out how we can have a child without using another rib."

Thus, the overarching consideration for solutions is empowering women, through awareness and education, that favorable lifestyle changes can not only decrease cardiovascular risk factors, but can prevent cardiovascular and coronary heart disease (CHD). ${ }^{1}$ This involves education of women and their healthcare providers regarding the substantial vulnerability to and adverse outcomes of CHD in women. It encompasses preventive heart-health behavioral changes by women, including their increased awareness of personal cardiovascular risk factors and the need for emergency care for acute cardiovascular events, and the reshaping of practice patterns by healthcare providers.

In the interim, a number of recommendations can be implemented. First is that a pregnancy history be included in the cardiovascular risk evaluation for women, including queries for gestational diabetes, preeclampsia, preterm birth, and small-for-gestational-age infant. ${ }^{2}$ Specifically, women with prior preeclampsia warrant early and intensive coronary risk intervention, with risk-factor screening as early as the first year postpartum because coronary risk factors have been reported to be manifest in the early years after delivery. ${ }^{3}$

An ideal pregnancy history includes ${ }^{4}$ : the number of pregnancies, the number of miscarriages, the number of pregnancies involving breast feeding, and the number of months for each pregnancy; whether any babies were born $>3$ weeks before the due date, how many, and did this occur spontaneously or was delivery early because of illness. Queries regarding preeclampsia in any pregnancy should identify in which pregnancy it occurred, how many times, early delivery because of preeclampsia, and how many weeks before due date delivery occurred. Additional history includes ascertainment of hypertension in any pregnancy, as well as proteinuria during pregnancy, and the weight of all babies and how many weeks before due date they were delivered.

Heightened preventive efforts are warranted in subpopulations of women, ${ }^{5,6}$ in that major disparities in cardiovascular health have an adverse impact on clinical outcomes and life quality. Particularly to be targeted are black and Hispanic women, in that there is increased hypertension among black women, increased diabetes among Hispanic women, and the highest coronary and cardiovascular mortality among black women. Cultural competence is requisite to ensure equitable care.

I view 6 items as highly relevant in targeting gender disparities and offering favorable prospects for the future:

1. Can a decrease in risk-factor burden delay the onset of clinical CHD?

2. Can a decrease in risk-factor burden improve the outcomes of clinical coronary events?

3. Can we decrease residual angina and resultant decreased activity tolerance and quality of life among women?

4. Can we decrease the excess bleeding encountered in multiple clinical coronary subsets of women?

5. Can we decrease the excess mortality, especially of younger women, who sustain myocardial infarction and coronary artery bypass graft surgery?

6. Can we improve the major socioeconomic issues disproportionate for women that impair health literacy: lack of access to affordable care, to health education, and to health information? ${ }^{7}$

These, indeed, are the rationales for examining gender differences in coronary heart disease.

\section{References}

1. Hayes SN, Johnson PA, Piña IL, et al. All about Eve: unique aspects of CVD in women. http://www.medscape.com/viewarticle/704684. Accessed January 24, 2011

2. Bannerjee M, Cruickshank JK. Pregnancy as the prodrome to vascular dysfunction and cardiovascular risk. Nat Clin Pract Cardiovasc Med. 2006;3;596-603

3. Smith GN, Walker MC, Liu A, et al; for the Pre-Eclampsia New Emerging Team (PE-NET). A history of preeclampsia identifies women who have underlying cardiovascular risk factors. $J \mathrm{Am}$ Obstet Gynecol. 2009;200:58.e1-58.e8.

4. Roberts JM, Hubel CA. Pregnancy: a screening test for later life cardiovascular disease. Womens Health Issues. 2010;20:304-307.

5. Smedley BD, Stith AY, Nelson AR, eds.; Committee on Understanding and Eliminating Racial and Ethnic Disparities in Health Care, Institute of Medicine. Unequal Treatment: Confronting Racial and Ethnic Disparities in Health Care. Washington, DC: National Academy Press; 2002.

6. Davis AM, Vinci LM, Okwuosa TM, et al. Cardiovascular health disparities: a systematic review of health care interventions. Med Care Res Rev. 2007;64(5 suppl):29S-100S.

7. Wenger NK. Coronary heart disease in women: highlights of the past 2 years-stepping stones, milestones, and obstructing boulders. Nat Clin Pract Cardiovasc Med. 2006;3:194-202. 